\title{
An Improved Method for Culturing Tradescantia Pollen Tubes for Chromosomal Analysis
}

\author{
Beyoung Hwa Kwack \\ Department of Horticulture, Korea University \\ Seoul, Korea \\ and \\ In-Hwan Kim
}

Office of Rural Development, Suwon, Korea

Receined Jamuary 10, 1966

\section{Introduction}

It is frequently necessary to obtain distinct chromosomes for cytological studies. The second mitosis in the growing pollen tubes of binucleate grains from many angiosperm species serves this purpose. The number of chromosomes at mitosis is haploid and the chromosomes line up in a lengthwise configuration along the pollen tube quite distinctively. Because of ease of handling and convenience of staining, pollen from Tradescantia has been extensively used in cytological studies. Advantages of this material were fully discussed earlier by Conger (1953) and Swanson (1940). Although this material has been successfully used in the studies of chromosomal analysis by a number of workers (Bishop 1949. Conger and Fairchild 1953, Evans and Neary 1959, Kirby-Smith and Craig 1957. Swanson 1944) obtaining adequate pollen tube growth and mitotic figures for chromosomal analysis has been the most difficult aspect of the technique. Therefore the authors were interested in establishing an improved method of pollen culture for cytological studies.

The authors have consistently observed that alignment of mitotic chromosumes in the growing pollen tubes is difficult to obtain unless sufficient elongation of the pollen tubes has taken place. The chromosomes in shorter pollen tubes are usually not seen, or if decernable, and are crowded in such a manner that analysis of the chromosomes is extremely difficult, such as identifying chromosomal aberrations due to irradiation, etc. It has been assumed from preliminary observations that the longer the pollen tubes, the more frequent and distinct are the mitotic figures. To accomplish this the present studies were undertaken

\section{Meterials and methods}

A large number of pollen grains from Tradescantia paludosa $(\mathrm{n}=6)$ Anderson and Woodson Clone 5 of Sax, were placed on dry $22 \times 22 \mathrm{~mm}$ or $22 \times 44 \mathrm{~mm}$ cover glasses which were then transferred to water-saturated Petri dishes containing two or three sheets of moistened filter paper. Upon pre-humidification of pollen for 15 to 20 minutes, approximately $1 / 25$ to $1 / 50$ $\mathrm{ml}$ of either medium "- $\mathrm{Ca}$ " or " $+\mathrm{Ca}$ " was dropped directly on the humidified pollen. Medium "Ca" contained $10 \%$ sucrose, $100 \mathrm{mg} / \mathrm{l}$ boric acid and $0.02 \%$ colchicine in distilled water, and medium "+ Ca" contained $300 \mathrm{mg} / 1 \mathrm{Ca}\left(\mathrm{NO}_{3}\right)_{2} \cdot 4 \mathrm{H}_{2} \mathrm{O}, 200 \mathrm{mg} / 1 \mathrm{MgSO}{ }_{4} \cdot 7 \mathrm{H}_{2} \mathrm{O}$ and $100 \mathrm{mg} / 1$ $\mathrm{KNO}_{3}$ in addition to the "- $\mathrm{Ca}$ ". The pollen was then stirred around with a small glass rod. It is preferable to make the shape of the drop round, 10 to $15 \mathrm{~mm}$ in diameter and less than $1 \mathrm{~mm}$ in depth. If the depth of the drop is greater. elongated tubes and metaphasic chromosomes becomes extremely crowded, resulting in difficulty of handling at the time of staining. Pollen was grown in the laboratory $\left(24^{\circ} \mathrm{C}\right)$ and metaphasic chromosomes were usually seen in six to eight hours after planting. 


\section{Observations}

The first mitotic figures with distinct chromosomes appeared as early as three hours after planting. However, well-defined mitotic figures showed an increase in number to the seventh hour of growth, after which, for some unknown reason, there was a gradual diminishing in frequency (Table 1). Perhaps this was due to factors such as microbial contamination and pollen bursting, etc. It is necessary to avoid microbial contamination which usually starts approximately 12 hours after planting, varying with the room temperature and sterility of the medium. After the pollen was extensively grown, the cover glasses were quickly inverted and placed on coated micro-slides (egg-albumin or other adhesives). Excess medium was removed and the regular aceto-carmine stain was introduced from one side of the cover glass. A piece of filter paper was placed along the other side of the cover

Table 1. Pollen tube growth and number of mitotic figures with analyzable chromosomes in pollen tubes of Tradescantia paludosa, as affected by calcium ions and $\mathrm{pH}$

\begin{tabular}{|c|c|c|c|c|}
\hline \multirow[b]{2}{*}{$\begin{array}{l}\text { Time required } \\
\text { for growth } \\
\text { (hours) }\end{array}$} & \multicolumn{2}{|c|}{$-\mathrm{Ca} *(\mathrm{pH} 5.3)$} & \multicolumn{2}{|c|}{$+\mathrm{Ca}(\mathrm{pH} 8.3)$} \\
\hline & $\begin{array}{l}\text { Pollen tube } \\
\text { length } \\
\text { (microns) }\end{array}$ & $\begin{array}{l}\text { No. of mitotic } \\
\text { figures }(96)\end{array}$ & $\begin{array}{l}\text { Pollen tube } \\
\text { length } \\
\text { (microns) }\end{array}$ & $\begin{array}{l}\text { No. of mitotic } \\
\text { figures }(96)\end{array}$ \\
\hline 1 & 141.2 & 0 & 656.6 & 0 \\
\hline 2 & 260.4 & 0 & 1501.5 & 0 \\
\hline 3 & 329.0 & 0 & 2047.5 & 3.2 \\
\hline 4 & 303.1 & 0 & 2278.5 & 10.1 \\
\hline 5 & 311.5 & 0 & 2361.8 & 12.5 \\
\hline 6 & 334.6 & 0 & 2397.5 & 17.3 \\
\hline 7 & 312.0 & 0 & 2527.0 & 18.4 \\
\hline 8 & 329.5 & 1.3 & 2419.9 & 18.3 \\
\hline 12 & 333.4 & 1.1 & 2405.2 & 15.5 \\
\hline 20 & 327.6 & 0 & 2411.0 & 9.3 \\
\hline
\end{tabular}

glass, so that the entire field of the glass became well diffused with the stain. Then the staining was checked under a microscope. Whenever a permanent preparation was needed the cover glass was pressed against the underlying slide, and the cover glass was removed by freezing over dry-ice. This slide was then handled according to the conventional methods of permanent preparation of slides. These methods were adequately described elsewhere by Conger and Fairchild (1953). It is recommended that analysis of the chromosomes be made immediately after staining, prior to permanent mounting. The difference in the number of distinct mitotic figures and analyzable chromosomes obtained when using either the standard medium ("-Ca") or the calcium-supplemented medium (" $+\mathrm{Ca}$ "), which were previously described, is shown in Table 1 . The present results indicate that calcium ions not only enhance pollen tube growth and initiate mitosis sooner, but also increase the number of mitotic figures with distinct chromosomes. Pollen 
growth in the above two different media is presented in Fig. 1.

\section{Discussion}

Calcium ions were formerly found to be a primary controlling factor of pollen tube growth (Brewbaker and Kwack 1963, Kwack 1965). The calcium activity, which results in increased resistance to pollen tube wall bursting (Brewbaker and Kwack 1963, Kwack 1965), seems to favor a low hydrogen-ion concentration. When the hydrogen-ion was relatively high (below $\mathrm{pH}$ 5.3), the effect of calcium could not be readily demonstrated. However, the pollen tube elongation was observed to be greater with calcium than without it. Similarly the high $\mathrm{pH}$ alone showed

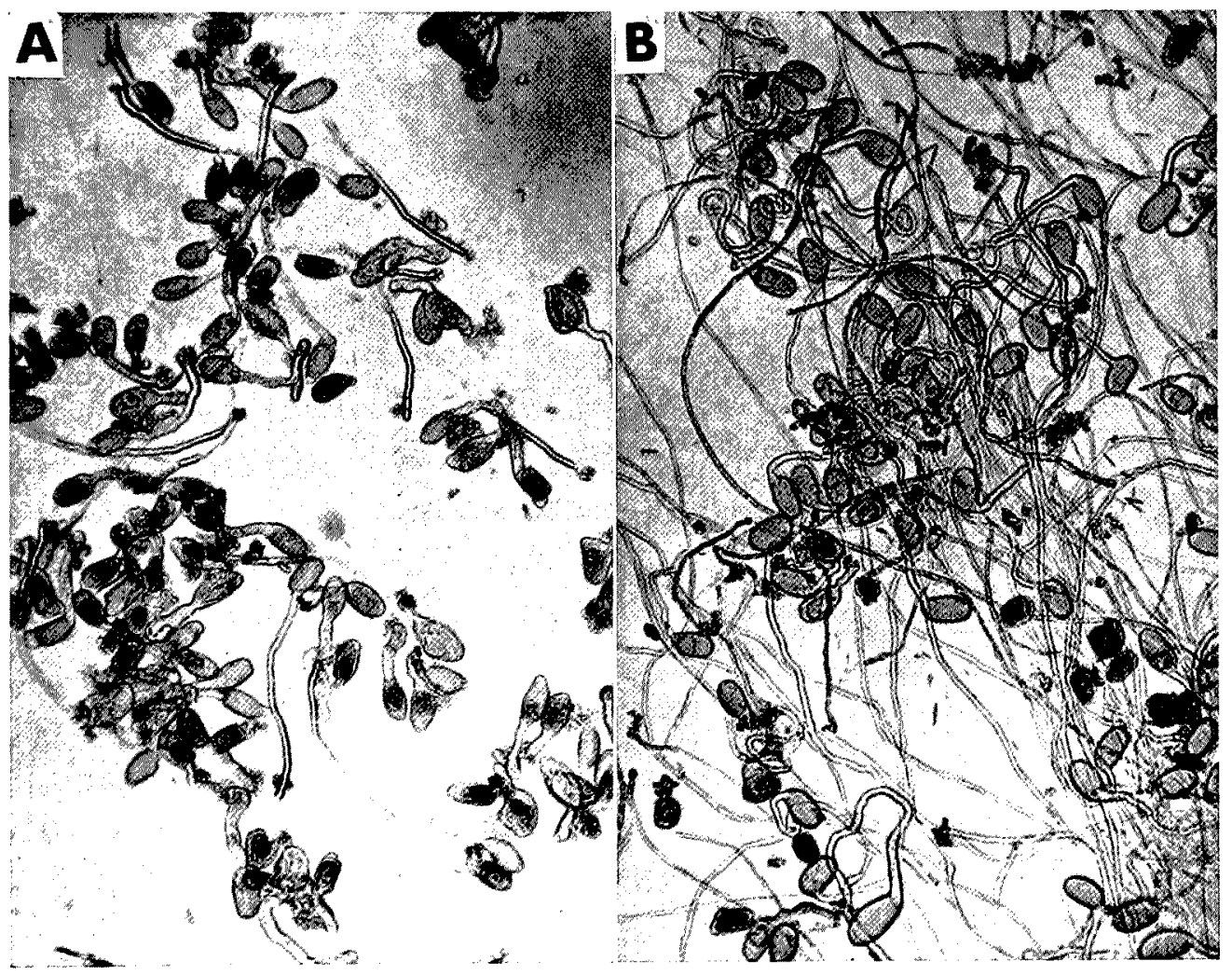

Fig. 1. The effect of calcium ions and $\mathrm{pH}$ on Tradescantia pollen growth. A, growth in "- $\mathrm{Ca}, \mathrm{pH}$ 5.3" medium. B. growth in " $+\mathrm{Ca}, \mathrm{pH} 8.3$ " medium.

less of an effect than did the combined calcium and high $\mathrm{pH}$, indicating that the calcium action favors a high $\mathrm{pH}$ (Kwack 1965). It was also found that the calcium activity requires either magnesium or potassium ions, or both (Brewbaker and Kwack 1963). Therefore the $\mathrm{pH}$ of medium " $+\mathrm{Ca}$ " was maintained at 8.3 and the medium included magnesium and potassium salts. The general appearance of the mitotic chromosomes grown in the calcium media is shown in Fig. 2.

Colchicine in the media not only inhibits the anaphasic movement of chromosomes and contracts them, but also enhances the calcium activity (Kwack and 


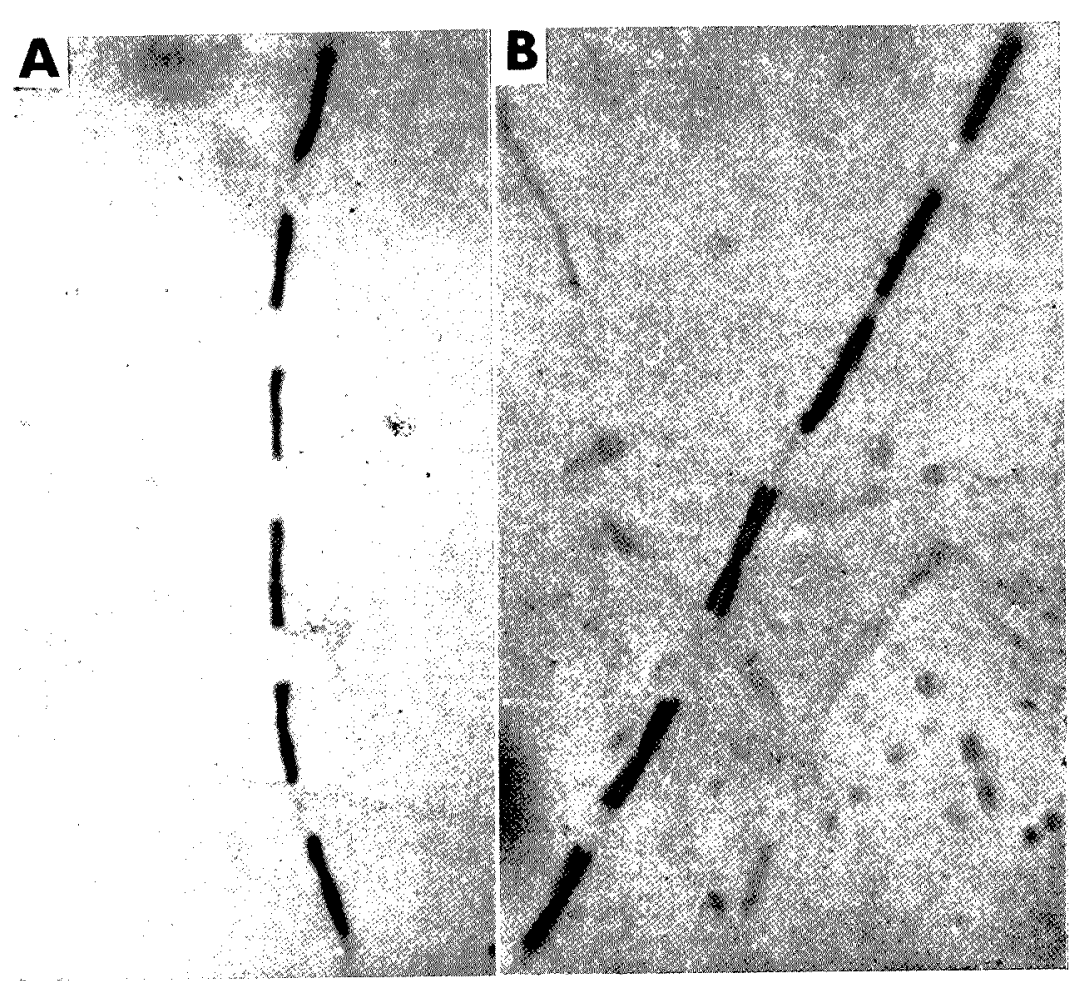

Fig. 2. Mitotic chromosomes in a pollen tube of Tradescantia paludosa $(\mathbf{n}=6)$ A, one example.

B, another example.
Macdonald 1965). Studies of the colchicine action in relation to calcium are under-way at this laboratory. It is interesting to note that the authors have found that an addition of $8 \%$ coconut milk to the calciumsupplemented medium gave extended tube elongation beyond that found with calcium supplement alone. This effect appears to be similar in nature to that of the effect observed with' colchicine (Kwack and Macdonald 1965).

\section{Summary}

By using pollen from Tradescantia paludosa, it was found that pollen cultural medium containing calcium, magnesium and potassium ions, at a high $\mathrm{pH}$, greatly enhanced growth of the pollen and accelerated the pollen mitosis. The calcium-supplemented medium, unlike conventional pollen growth media, facilitated well aligned mitotic chromosomes in the pollen tubes, resulting in a more distinct appearance of the chromosomes. This allowed the obtaining of more analyzable chromosomes in the pollen tubes.

\section{Acknowledgment}

A part of this work was conducted at the University of Hawaii with the assistance of the U.S. National Science Foundation Grant G-21258.

\section{Literature cited}

Bishop, C.J. 1949. Pollen tube culture on a lactose medium. Stain Tech. 24: 9-12.

Brewbaker, J.L. and Kiwack, B.H, 1963. The essential role of calcium ion in pollen germination and pollen tube growth. Amer. Jour: Bot: 50: 859-865. 
Conger, A.D. 1953. Culture of pollen tubes for chromosomal analysis at the pollen tube division. Stain Tech. 28: 281-283

_- and Fairchild, L.M. 1953. A quick-freeze method for making smear slide permanent. Stain Tech. 28: 281-283.

Evans, H.J. and Neary, G.H. 1959. The infuence of oxygen on the sensitivity of Tradescantia pollen tube chromosomes to X-rays. Rad. Res. 11:636-641.

Kirby-Smith, J. and Craig, D.L. 1957. The induction of chromosome aberrations in Tradescantia by ultraviolet radiation. Genetics 42: 176-187.

Kwack, B.H. 1965. The effect of calcium on pollen germination. Proc. Amer. Soc. Hort. Sci. $86: 818-823$.

- and Macdonald, T. 1965. The role of calcium on pollen growth as expressed by various water-soluble substances. Bot. Mag. (Tokyo) 78: 163-170.

Swanson, C.P. 1940. The use of acenaphthene in pollen tube technic. Stain Tech. 15: 49-52.

-1944. X-ray and ultraviolet studies on pollen tube chromosomes. I. The effect of ultraviolet (2537 A) on x-ray-induced chromosomal aberrations. Genetics 29:61-68. 